A C T A C H E M I C A S C A N D I N A V I C A 19 (1965) $1071-1078$

\title{
Amino Acids and $\gamma$-Glutamyl Derivatives in Seeds of Lunaria annua L. Part II*
}

\author{
P. OLESEN LARSEN \\ Department of Organic Chemistry, The Royal Veterinary and Agricultural College, \\ Copenhagen, Denmark
}

\begin{abstract}
In continuation of studies on the contents of ninhydrin-reacting constituents in unhydrolyzed seed extracts of Lunaria annua L., $\mathrm{N}^{5}$-isopropyl-L-glutamine, not previously found in nature, and $\gamma$-glutamyl- $\gamma$-aminobutyric acid, previously only tentatively identified in nature, have been isolated and identified by comparison with synthetic samples prepared by conventional methods. $\alpha$-Aminoadipic acid, $\beta$-alanine, $(-)-\beta$-aminoisobutyric acid, $\gamma$-aminobutyric acid, and $\gamma$-guanidobutyric acid, all previously known from higher plants, have been isolated in crystalline form. The structure of a new amino acid and two sulphur-containing derivatives of glutamic acid remain to be elucidated.
\end{abstract}

Tn a previous communication ${ }^{1}$ a detailed account was given of the acidic Ininhydrin-reacting constituents of Lunaria annua L. In addition, tentative identifications of some of the neutral compounds were presented. Studies of the latter have been continued as reported in the present communication with the double purpose of substantiating the previous identifications and identifying some of the unknown constituents. In addition, final identification has been made of two of the minor acidic constituents.

In order to identify the constituents of the neutral fraction of amino acids, it became necessary to employ preparative ion-exchange chromatography. Whereas the methods for preparative ion-exchange chromatography of acidic amino acids are very satisfactory, those available for separating larger amounts of neutral amino acids are not very efficient, especially because of the small capacity employed in most of the described methods. In the present investigation a modification of the procedure of Liebster et al. ${ }^{2}$ was used: a strongly acidic ion exchange resin in the pyridinium form is eluted with pyridineformic acid and pyridine-acetic acid buffers. Since the column used was smaller than that described and since the column was heavily overloaded the separation of the neutral amino acids was far from complete. The result of the prepar-

* Part I. Acta Chem. Scand. 16 (1962) 1511. 


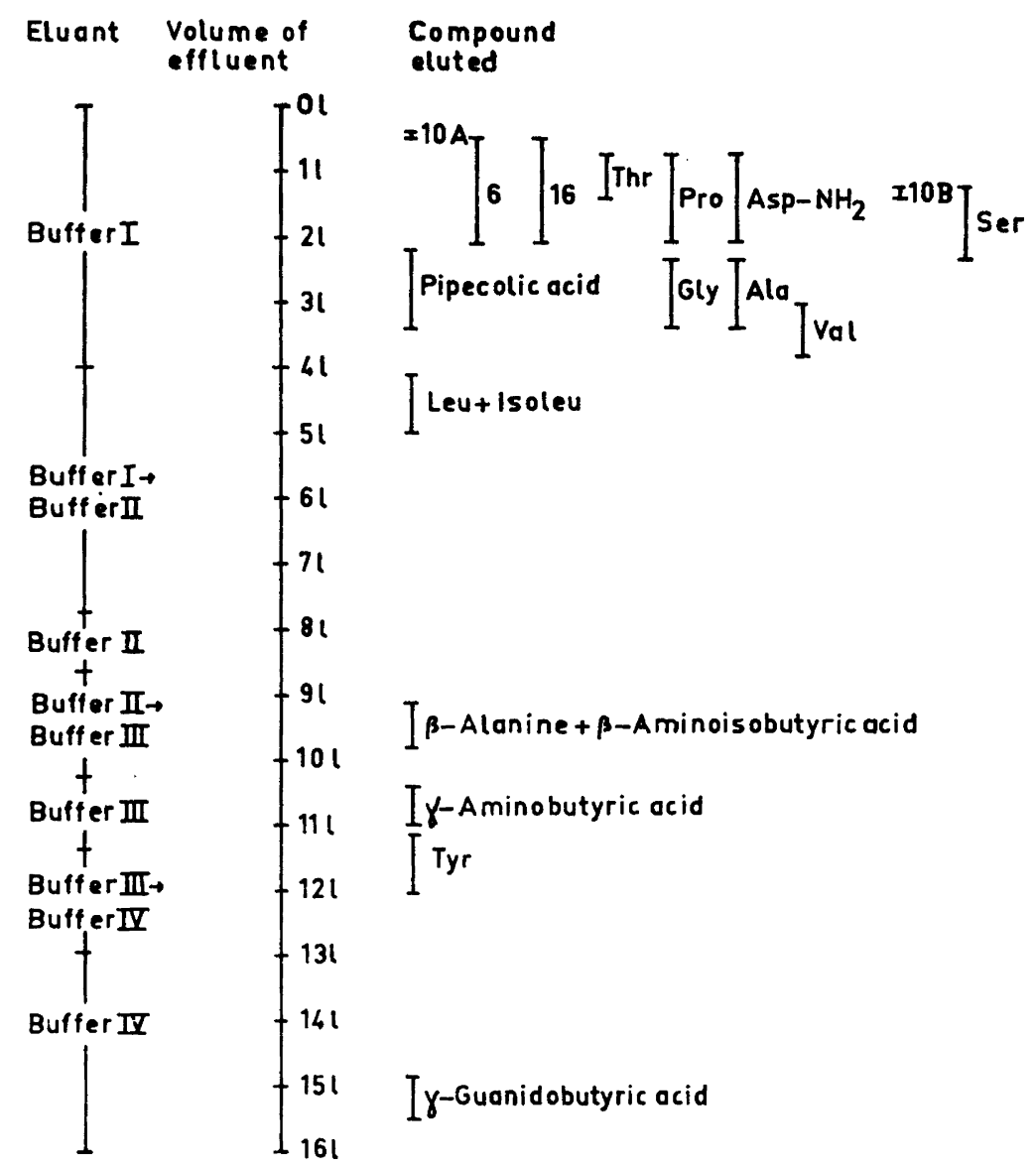

Fig. 1. Fractionation of the neutral amino acids from seed extracts of Lunaria annua L. on a Dowex $50 \mathrm{~W} \times 8,200-400$ mesh, ion exchange column, $3.4 \times 97 \mathrm{~cm}$. For composition of buffers and other experimental conditions, see Fxperimental. The numbers refer to the numbers of the unknown compounds on Fig. 1 in the preceding communication (Ref. 1). No. 16 has been identified as $\mathrm{N}^{5}$-isopropyl-L-glutamine.

ative ion exchange operation is outlined in Fig. 1. The numbers refer to those of the unknown compounds in Fig. 1 of the preceding communication. ${ }^{1}$

The neutral derivative of glutamic acid, previously referred to as No. 16, appeared in fractions together with several of the ordinary amino acids. The high $R_{F}$-values of No. 16 and its complete separation from other amino acids with high $R_{F}$-values such as valine, leucine, isoleucine, and $\gamma$-guanidobutyric acid during the ion exchange chromatography made it possible, however, to obtain it in pure form by preparative paper chromatography.

The purified sample had the elemental composition $\mathrm{C}_{8} \mathrm{H}_{16} \mathrm{~N}_{2} \mathrm{O}_{3}$. Acid hydrolysis liberated partially racemized L-glutamic acid and isopropylamine. 
Glutamic acid prepared from L-glutamine by the same procedure underwent the same degree of racemization. The extent of racemization was much larger than would be expected from the recorded data on racemization of glutamic acid with strong acid. ${ }^{3}$ Isopropylamine was isolated as the hydrochloride. By quantitative determination of $\alpha$-amino- $\mathrm{N}$ by the manometric Van Slyke procedure $^{4}$ the theoretical value for an $\alpha$-amino acid was found, indicating that isopropylamine was bound to the $\gamma$ - and not to the $\alpha$-carboxyl group. ${ }^{5}$ A reference sample of the hitherto unknown $\mathrm{N}^{5}$-isopropyl-L-glutamine (I) was synthesized according to traditional methods (cf. Experimental). The synthetic sample was indistinguishable from the natural product with regard to IRspectra, paperchromatographic behaviour and optical rotation.

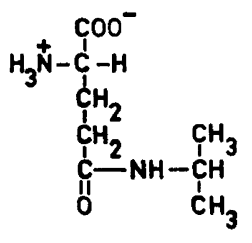

I

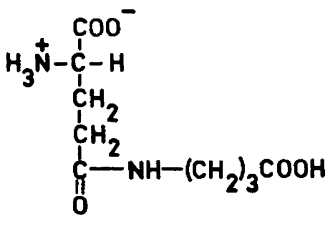

II

The neutral derivative of glutamic acid, previously referred to as No. 10,1 obviously was a mixture of two compounds, none of which has yet been obtained in analytical pure form. Both are derived from glutamic acid and a sulphur-containing component and undergo partial destruction upon acid hydrolysis. An investigation to establish the identity of the two compounds is in progress.

Again, the neutral amino acid No. $6^{1}$ has not yet been obtained in analytical pure form. On treatment of the amino acid with strong acid a new compound is observed on paper chromatograms, presumably a lactone of the amino acid. By using various detection reagents it could be shown that the amino acid on paper chromatograms consumes periodate ${ }^{6}$ accompanied by the liberation of ammonia, ${ }^{7}$ formaldehyde and acetaldehyde. ${ }^{8}$ Further progress in the identification must await the isolation of new material.

$\beta$-Alanine and $\beta$-aminoisobutyric acid occurred in the same fractions but were easily separated by preparative paper chromatography. Both were identified on comparison with authentic samples. The isolated $\beta$-aminoisobutyric acid showed a negative rotation value and therefore possesses $(R)$-configuration. ${ }^{9}$

$\gamma$-Aminobutyric acid occurred uncontaminated with other compounds and was easily obtained crystalline. The identity was established by comparison with authentic material. $\gamma$-Guanidobutyric acid also appeared uncontaminated with other compounds and was identified upon comparison with an authentic sample.

In the previous communication ${ }^{1}$ one of the acidic compounds was tentatively identified as a glutamyl-derivative of $\gamma$-aminobutyric acid. In order to establish which carboxyl group was involved in the amide bond, 
$\gamma$-L-glutamyl- $\gamma$-aminobutyric acid (II) was synthesized by standard methods (cf. Experimental).

A small quantity of the natural product was isolated in the crystalline state and proved to be identical with the synthetic material by comparison of IR-spectra and in their paperchromatographic behaviour. The available amount of the natural compound was too small to permit determination of its optical rotation.

According to private information the same compound has been synthesized elsewhere by a different route. ${ }^{10}$ The two synthetic compounds have been compared and proved to be identical. The isomeric $\alpha$-L-glutamyl- $\gamma$-aminobutyric acid has been prepared in the same laboratory, and the two isomers are easily distinguishable by paper chromatography. ${ }^{10}$

A glutamyl derivative of $\gamma$-aminobutyric acid has previously been identified in a chloramphenicol-treated Escherichia coli strain. ${ }^{11}$ The further identity of this compound has not yet been established.

The acidic compound previously referred to as No. $2^{1}$ has been isolated in crystalline, partially pure form. Its identity with $\alpha$-aminoadipic acid was shown by comparison of the IR-spectra. The amount isolated did not permit determination of the optical rotation.

As discussed in the preceding communication ${ }^{1}$ the occurrence of $\beta$-alanine, $\beta$-aminoisobutyric acid, $\gamma$-aminobutyric acid and $\gamma$-guanidobutyric acid in higher plants has been established earlier. $\alpha$-Aminoadipic acid also seems to be widely distributed in nature, ${ }^{12}$ whereas the two $\gamma$-glutamyl-derivatives have not been previously encountered in nature. In recent years several other $\gamma$-glutamyl derivatives of amino acids have been found in the plant kingdom. ${ }^{13}$ Most of these are acidic, composed of glutamic acid and a neutral amino acid. This may be associated with the fact that acidic ampholytes are more easily obtained in pure state from biological material.

The nearest analogue of $\mathrm{N}^{5}$-isopropyl-L-glutamine found in nature is theanine, $\mathrm{N}^{5}$-ethyl-L-glutamine, isolated from tea leaves. ${ }^{14}$ Enzymic synthesis of theanine from glutamic acid, ethylamine, and adenosinetriphosphate has been demonstrated in homogenates of tea seedlings, in extracts of pea-seed acetone powder, and in extracts of pigeon liver acetone powder. ${ }^{15,17}$ This biosynthesis may be due to a nonspecific reaction of glutamine synthetase or $\gamma$-glutamylcysteine synthetase. ${ }^{17}$ By analogy it appears conceivable that the occurrence of the isopropylamine derivative in Lunaria annua $\mathrm{L}$. is attributable to the occurrence of isopropylamine in this plant. However, this amine seems to have been encountered only in one natural source viz. ergot.18

In this connexion it may also be of interest that Lunaria annua $\mathrm{L}$. contains glucoputranjivin, a thioglucoside which upon enzymic hydrolysis produces isopropyl isothiocyanate. ${ }^{19} \mathrm{~A}$ similar relationship has been observed in Sinapis alba L. which contains sinalbin, a thioglucoside which upon enzymic hydrolysis produces $p$-hydroxybenzyl isothiocyanate ${ }^{20}$ and which has recently been shown to contain $p$-hydroxybenzylamine, not previously isolated from natural sources. $^{21}$ 


\section{EXPERIMENTAL}

Microanalyses were performed by Mr. G. Cornali.

Where not otherwise stated rotations were measured in a $1 \mathrm{dm}$ tube. Determinations performed in an $0.5 \mathrm{dm}$ tube are designated 'microdetermination'. Melting points were determined in capillary tubes in an Anschütz-Hershberg apparatus equipped with fully immersed thermometers. The standard rate of heating was $2^{\circ}$ per min.

The various compounds isolated were purified by use of preparative paper chromatography, ion exchange resins, and small columns of deactivated carbon.

Preparative paper chromatography was performed on Whatman paper No. 3 MM in butanol:acetic acid:water (12:3:5) and in phenol:water:conc. ammonia (120:30:1). The sheets of paper were $22 \mathrm{~cm}$ broad and usually $10 \mathrm{mg}$ of amino acid mixtures were applied to each sheet.

The ion exchange resins used were either strongly acidic (Dowex $50 \mathrm{~W} \times 8,200-$ 400 mesh) in the hydrogen form, with subsequent elution of the amino acids with aqueous ammonia or aqueous pyridine, or strongly basic (Dowex 1 X 8, 200-400 mesh) in the acetate form with subsequent elution with dilute acetic acid. The amount of resin used was between 0.5 and $2 \mathrm{ml}$.

The columns with deactivated carbon were prepared from active carbon (Darco G 60) washed with $\mathrm{HCl}$ and subsequently deactivated with stearic acid. ${ }^{22}$ Four grams of stearic acid was used per $100 \mathrm{~g}$ of carbon. The columns usually contained $250 \mathrm{mg}$ of carbon in a $1 \mathrm{~cm}$ layer supported by a small layer of celite and a sintered glass funnel. The neutral compounds were eluted with water from the columns, whereas dilute acetic acid was required to remove the acidic compounds ( $\gamma$-glutamyl- $\gamma$-aminobutyric acid and $\alpha$-aminoadipic acid). This may possibly be of value in small scale separation of acidic amino acids and peptides from neutral ones.

All solvents from the various eluates were removed by evaporation under reduced pressure. The last traces of acetic acid, ammonia and pyridine were removed by repeated evaporations with water. All isolated compounds were homogeneous on paper chromatography; the identities were confirmed by co-chromatography with authentic samples.

\section{Is o lations}

Fractionation of the neutral amino acids on a strongly acidic ion exchange resin. A column of Dowex $50 \mathrm{~W} \times 8,200-400$ mesh, $3.4 \times 97 \mathrm{~cm}$, was used. The resin was treated with $\mathrm{NaOH}$ and $\mathrm{HCl}$, transferred into the pyridinium form and equilibrated with the first buffer solution as described. ${ }^{2}$ Four of the five buffer solutions described ${ }^{2}$ were used for the separation:

\footnotetext{
Buffer I: Initial pyridine concentration $0.1 \mathrm{M}, \mathrm{pH} 3.1$ obtained by addition of formic acid.

Buffer II: Initial pyridine concentration $0.2 \mathrm{M}, \mathrm{pH} 3.1$ obtained by addition of formic acid.

Buffer III: Initial pyridine concentration $0.2 \mathrm{M}$, pH 4.4 obtained by addition of acetic acid.

Buffer IV: Initial pyridine concentration $1.0 \mathrm{M}, \mathrm{pH} 5.1$ obtained by addition of acetic acid.
}

The fraction of neutral amino acids from Lunaria annua L. described in the preceding communication ${ }^{1}$ (3.4 g) was dissolved in $13 \mathrm{ml}$ of buffer $\mathrm{I}$ and applied to the column. The column was eluted with the different buffers as indicated in Fig. 1. Change from one buffer to the next was made gradually by a mixing device. During the first 4.81 , fractions of 200 drops $(12.5 \mathrm{ml})$ were collected. Thereafter the size of the fractions were changed to 350 drops $(22 \mathrm{ml})$. All fractions were inspected by spot-test with ninhydrin and Sakaguchi's reagent and some of the fractions also by one and two dimensional paper chromatography. A total of 942 fractions was collected. The rate of flow was $45 \mathrm{ml} / \mathrm{h}$. The result of the fractionation is indicated in Fig. 1. The buffers were removed from the fractions containing amino acids by evaporation under reduced pressure. The last traces

Acta Chem. Scand. 19 (1965) No. 5 
of pyridine, formic acid and acetic acid were removed by repeated evaporations with water.

Isolation of $N^{5}$-isopropyl-1-glutamine. This compound was obtained from fractions 38-171. Purification was accomplished by preparative paper chromatography of the contents of fractions 38-60 and 101-114, first in phenol:water:ammonia, and thereafter in butanol:acetic acid:water, and of the contents of fractions 61-100 and 115-171 in butanol:acetic acid:water. Further purification was performed with a strongly acidic ion exchange resin (elution with ammonia) and a carbon column. The crystalline residue from the last column was recrystallized from water: ethanol to give a pure sample $(19 \mathrm{mg})$, $[\alpha]_{\mathrm{D}}{ }^{24}+6^{\circ}(c 1.75$, water, microdetermination). (Found: C 51.02; H 8.60; $\mathrm{N} \mathrm{14.94.} \mathrm{Calc.} \mathrm{for}$ $\mathrm{C}_{8} \mathrm{H}_{18} \mathrm{~N}_{2} \mathrm{O}_{3}$ : C 51.05; $\mathrm{H}$ 8.57; $\mathrm{N}$ 14.88). The quantitative ninhydrin determination was performed on a solution containing $1.47 \mathrm{mg}$ of the compound per $\mathrm{ml}$. Three analyses gave the values: $0.105,0.105$, and $0.108 \mathrm{mg}$ of $\alpha$-amino- $\mathrm{N}$ per $\mathrm{ml}$ solution. This corresponds to an average value of $7.2 \% \alpha$-amino- $\mathrm{N}$ in the compound (theoretical: $7.44 \%$ ).

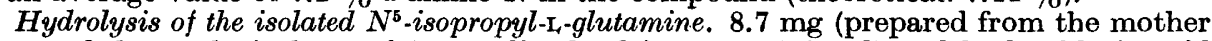
liquor of the analytical sample) was dissolved in water $(500 \mu \mathrm{l})$ and hydrochloric acid $(500 \mu \mathrm{l}, 1 \mathrm{~N})$, and the solution was heated in a closed ampoule for $16 \mathrm{~h}$ at $110^{\circ}$. After cooling the solution was evaporated under reduced pressure to give a semicrystalline residue. The residue was taken up in water $(125 \mu \mathrm{l})$ and $\mathrm{NaOH}(100 \mu \mathrm{l}, 10 \mathrm{~N})$ was added. The liberated amine was swept into a tube containing $\mathrm{HCl}(500 \mu \mathrm{l}, 0.1 \mathrm{~N})$ by a stream of air. The solution of the amine in hydrochloric acid was evaporated under reduced pressure. The evaporation was repeated after the addition of water and twice after the addition of $96 \%$ ethanol. The IR-spectrum of the crystalline residue $(2.6 \mathrm{mg})$ was identical with that of isopropylamine hydrochloride prepared in the same way. For comparison, propylamine hydrochloride and methylethylamine hydrochloride were prepared in the same way and the IR-spectra recorded.

The basic solution remaining after the removal of the isopropylamine was diluted with water and brought to $\mathrm{pH} 1.5$ by the addition of HCl. Purification of the glutamic acid was accomplished by use of a strongly acidic ion exchange resin (elution with ammonia) and a strongly basic ion exchange resin. The crystalline residue from the last column $(5.2 \mathrm{mg})$ was recrystallized from ethanol-water to give a pure sample $(3.6 \mathrm{mg})$, $[\alpha]_{546}{ }^{24}+13^{\circ}(c \quad 0.6,1 \mathrm{~N} \mathrm{HCl}$, microdetermination) (Lit. value for $\mathrm{L}$-glutamic acid $\left.[\alpha]_{546}+38^{\circ}(5 \mathrm{~N} \mathrm{HCl})^{23}\right)$. The IR-spectrum was very similar to that of DL-glutamic acid. acid.

Treatment of t.-glutamine in the same way also led to partly racemized L-glutamic

Isolation of unknown compound No. $10 \mathrm{~A}$. This compound was obtained from fractions 34-37 (containing the front of the amino acid mixture). Purification was achieved by use of a strongly acidic ion exchange resin (elution with ammonia), a carbon column, preparative paper chromatography, first in phenol:water:ammonia and secondly in butanol:acetic acid:water, a strongly acidic ion exchange resin (elution with ammonia), a carbon column and a strongly acidic ion exchange resin (elution with pvridine). The residue from the last column $(12 \mathrm{mg})$ crystallized on trituration with ethanol. The presence of sulphur (micro-test ${ }^{24}$ ) and of sulphoxide groups (colour reaction on paper chromatograms ${ }^{25}$ ) were demonstrated. By hydrolysis with $\mathrm{HCl}$ glutamic acid was produced together with two or three minor ninhydrin reacting components.

Isolation of unknown compound No. 10 B. This was obtained from fractions 101-114. Purification was accomplished by preparative paper chromatography first in phenol: water:ammonia and secondly in butanol:acetic acid:water, a strongly acidic ion exchange resin (elution with ammonia), and a carbon column. A crystalline residue $(8 \mathrm{mg}$ ) was obtained. The compound had the same properties as No. $10 \mathrm{~A}$ with regard to the contents of sulphur, sulphoxide groups, and liberation of glutamic acid and minor ninhydrin reacting components on hydrolysis with $\mathrm{HCl}$.

Isolation of unknown compound No. 6. This was obtained from fractions 38-60. Purification was accomplished by preparative paper chromatography in phenol:water: ammonia, a strongly acidic ion exchange resin (elution with ammonia), and a carbon column. A crystalline sample $(18 \mathrm{mg})$, slightly contaminated with asparagine was obtained.

Isolation of $\beta$-alanine and (-)-ק-aminoisobutyric acid. These were obtained from fractions $591-617$. Separation was accomplished by preparative paper chromatography in butanol:acetic acid:water. The $\beta$-alanine eluted from the paper was purified by use of a strongly acidic ion exchange resin (elution with pyridine), a carbon column, and 
recrystallization from ethanol-water. A pure sample $(15 \mathrm{mg})$ was obtained with an IRspectrum identical with that of an authentic sample.

The $\beta$-aminoisobutyric acid eluted from the paper was purified in the same way. Recrystallization was performed from absolute ethanol to give a pure sample (17 $\mathrm{mg})$, $[\alpha]_{D^{24}}-12.4^{\circ}\left(c 0.95\right.$, water) (Lit. value $[\alpha]_{D^{17}}-14.2^{\circ}\left(c 0.42\right.$, water) $\left.{ }^{9}\right)$, with an IR-spectrum indistinguishable from that of an authentic sample of $(-)-\beta$-aminoisobutyric acid.

Isolation of $\gamma$-aminobutyric acid. This was obtained from fractions $645-670$. Purification was achieved by use of a strongly acidic ion exchange resin (elution with pyridine), a carbon column, and recrystallization from ethanol-water. A pure sample $(5 \mathrm{mg})$ was obtained with an IR-spectrum identical with that of an authentic sample.

Isolation of $\gamma$-guanidobutyric acid. This compound was obtained from fractions $847-872$. Purification was accomplished by use of a strongly acidic ion exchange resin (elution with ammonia), a carbon column, and two recrystallizations from water. A pure sample $(68 \mathrm{mg})$ with an IR-spectrum identical with that of an authentic sample was obtained.

Isolation of $\alpha$-aminoadipic acid. In the fractionation of the acidic amino acid and $\gamma$-glutamyl derivatives on a Dowex $1 \times 8$ column, described in the previous communication, ${ }^{1}$ fractions 98-99 contained small amounts of two unknown compounds (No. 2 and No. 9 on Fig. 1 in the previous communication). Fraction 99 was evaporated to dryness, and isolation of $\alpha$-aminoadipic acid was accomplished by preparative paper chromatography (on Whatman paper No. 1) in phenol:water:ammonia, a strongly acidic ion exchange resin (elution with pyridine), a carbon column, and a strongly basic ion exchange resin. The crystalline residue from the last column $(0.6 \mathrm{mg})$ showed an IR-spectrum similar to that of an authentic sample of $L_{-}-\alpha$-aminoadipic acid, though not with very sharp peaks.

Isolation of $\gamma$-glutamyl- $\gamma$-aminobutyric acid. In the fractionation of the acidic amino acids and $\gamma$-glutamyl derivatives on a Dowex $1 \times 8$ column described in the previous communication, ${ }^{1}$ fractions $73-79$ contained small amounts of this compound. Purification was accomplished by preparative paper chromatography in butanol:acetic acid:water, a strongly basic ion exchange resin, and a carbon column. A crystalline sample (4 $\mathbf{m g})$ was obtained by trituration of the residue from the last column with ethanol. The IR. spectrum was similar to that of the synthetic sample although not with very sharp peaks.

\section{Sy $\mathrm{ntheses}$}

$N^{2}$-Carbobenzoxy- $N^{5}$-isopropyl-L-glutamine benzyl ester (III). To a solution of carbobenzoxy-L-glutamic acid $\alpha$-benzyl ester $(257 \mathrm{mg}$, Cyclo Chemical Corporation) and tributylamine $(200 \mu \mathrm{l})$ in dioxane $(3 \mathrm{ml})$ at $5^{\circ}$ was added ethyl chloroformate $(80 \mu \mathrm{l})$. After $30 \mathrm{~min}$ isopropylamine $(100 \mu \mathrm{l})$ was added under stirring. The solution was gradually heated to room temperature in the course of one hour. Dioxane $(1.5 \mathrm{ml})$ and ethyl acetate $(10 \mathrm{ml})$ was added, and the solution was extracted with $\mathrm{HCl}(15 \mathrm{ml} 0.5 \mathrm{~N})$, sodium hydrogen carbonate solution $(2 \times 15 \mathrm{ml}, 5 \%)$ and water $(15 \mathrm{ml})$, dried over sodium sulphate, and evaporated to dryness. Two crystallizations from ethyl acetate-pentane afforded a pure sample $(150 \mathrm{mg}, 54 \%)$, m.p. $142-142.5^{\circ},[\alpha]_{\mathrm{D}^{21}}-15.9^{\circ}\left(c 1.0, \mathrm{CH}_{3} \mathrm{OH}\right)$. (Found: C 66.80; $\mathrm{H} 6.82 ; \mathrm{N}$ 6.71. Calc. for $\mathrm{C}_{23} \mathrm{H}_{28} \mathrm{O}_{5} \mathrm{~N}_{2}: \mathrm{C} 66.97 ; \mathrm{H} \mathrm{6.84} ; \mathrm{N} 6.79$ ).

$N^{5}$-Isopropyl-1-glutamine (I). To a solution of (III) $(145 \mathrm{mg})$ in methanol $(10 \mathrm{ml})$, water $(2 \mathrm{ml})$, and glacial acetic acid $(2 \mathrm{ml})$, palladium black was added. ${ }^{26}$ Hydrogen was introduced under stirring until the carbon dioxide evolution ceased. After filtration the solution was evaporated to dryness. The crystalline residue was recrystallized twice from ethanol:water to give a pure sample $(43 \mathrm{mg}, 65 \%),[\alpha]_{\mathrm{D}}{ }^{22}+7.1^{\circ}$ (c 1.7, water). (Found: $\mathrm{C}$ 50.72; $\mathrm{H}$ 8.65; $\mathrm{N}$ 14.85).

$\gamma$-Aminobutyric acid benzyl ester p-toluenesulphonic acid salt (IV). $\gamma$-Aminobutyric acid $(5.15 \mathrm{~g}), p$-toluenesulphonic acid, $\mathrm{H}_{2} \mathrm{O}(9.7 \mathrm{~g})$, benzyl alcohol $(20 \mathrm{ml})$ and benzene $(15 \mathrm{ml})$ were heated under reflux with continuous removal of water for $2 \mathrm{~h}$. After cooling the product was precipitated by the addition of dry ether. The salt was purified by dissolution in methanol, treatment with carbon, and reprecipitation with ether to give colourless crystalline material $(13.0 \mathrm{~g}, 71 \%)$. A sample for analysis was obtained by

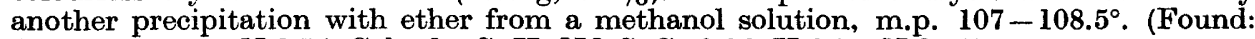
C 59.27; $\mathrm{H} 6.36 ; \mathrm{N} 3.74$. Calc. for $\mathrm{C}_{18} \mathrm{H}_{23} \mathrm{NO}_{5} \mathrm{~S}: \mathrm{C} 59.16 ; \mathrm{H} 6.34 ; \mathrm{N} \mathrm{3.83}$ ).

Acta Chem. Scand. 19 (1965) No. 5 


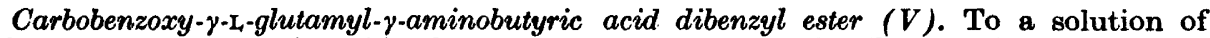
carbobenzoxy-L-glutamic acid $\alpha$-benzyl ester $(259 \mathrm{mg})$ and tributylamine $(200 \mu \mathrm{l})$ in dioxane $(3 \mathrm{ml})$ at $5^{\circ}$, ethyl chloroformate $(80 \mu \mathrm{l})$ was added. After $30 \mathrm{~min}$, a suspension of (IV) $(320 \mathrm{mg})$ and tributylamine $(230 \mu \mathrm{l})$ in dioxane $(4 \mathrm{ml})$ was added under stirring. The solution was gradually heated to room temperature in the course of one hour. Ethyl acetate $(10 \mathrm{ml})$ was added and the solution was extracted with $\mathrm{HCl}(15 \mathrm{ml} 0.5 \mathrm{~N})$, sodium hydrogen carbonate solution $(2 \times 15 \mathrm{ml} 5 \%)$ and water $(15 \mathrm{ml})$, dried over sodium sulphate and evaporated to dryness. Recrystallization from ethyl acetate-pentane gave a yield of $242 \mathrm{mg}(64 \%)$. A sample for analysis was obtained by recrystallization from methanol:water and subsequently from ethyl acetate:pentane, m.p. 104.5-106 ${ }^{\circ}$, $[\alpha]_{D^{22}}-10.3^{\circ}$ (c 1.0, $96 \%$ ethanol). (Found: C 67.97; $\mathrm{H}$ 6.35; $\mathrm{N}$ 4.97. Calc. for $\mathrm{C}_{31} \mathrm{H}_{34} \mathrm{~N}_{2} \mathrm{O}_{7}$ : C 68.11; H 6.27; N 5.13).

$\gamma-\mathrm{L}_{-}$-Glutamyl- $\gamma$-aminobutyric acid (II). To a solution of (V) (205 $\left.\mathrm{mg}\right)$ in methanol $(10 \mathrm{ml})$, water $(2 \mathrm{ml})$, and acetic acid $(2 \mathrm{ml})$, palladium black (100 mg) was added. Hydrogen was introduced under stirring until the evolution of carbon dioxide ceased. After filtration the solution was evaporated to dryness. The crystalline residue was recrystallized from ethanol-water to give a chromatographically pure sample (72 $\mathrm{mg}$, $83 \%),[\alpha]_{\mathrm{D}}{ }^{23}+5.2^{\circ}$ (c 0.9 , water). Two recrystallizations from ethanol-water afforded a sample for analysis. (Found: $\mathrm{C} \mathrm{46.46;} \mathrm{H} \mathrm{6.97;} \mathrm{N} 12.07$. Calc. for $\mathrm{C}_{9} \mathrm{H}_{16} \mathrm{~N}_{2} \mathrm{O}_{5}$ : $\mathrm{C}$ 46.54; H 6.95; N 12.06).

The author expresses his gratitude to Dr. H. D. Law for unpublished information on the synthesis of and for samples of $\gamma$-L-glutamyl- $\gamma$-aminobutyric acid and $\alpha$-L-glutamyl$\gamma$-aminobutyric acid, to Dr. K. Balenovic for a sample of $(-)$ - $\beta$-aminoisobutyric acid and to Dr. E. P. Abraham for a sample of $\mathrm{L}_{-}-\alpha$-aminoadipic acid.

\section{REFERENCES}

1. Larsen, P. O. Acta Chem. Scand. 16 (1962) 1511.

2. Liebster, J., Dobiásova, M., Kopoldova, J. and Ekl, J. Collection Czech. Chem. Commun. 26 (1961) 1700.

3. Wiltshire, G. H. Biochem. J. 55 (1953) 46.

4. VanSlyke, D. D., Dillon, R. T., MacFadyen, D. A. and Hamilton, P. J. Biol. Chem. 141 (1941) 627.

5. Sachs, H. and Brand, E. J. Am. Chem. Soc. 75 (1953) 4608.

6. Metzenberg, R. L. and Mitchell, H. K. J. Am. Chem. Soc. 76 (1954) 4187.

7. Consden, R. Nature 162 (1948) 359.

8. Schwarz, D. P. Anal. Chem. 30 (1955) 1855.

9. Balenović, K. and Bregant, N. Tetrahedron 5 (1959) 44.

10. Fosker, A. P. and Law, H. D. J. Chem. Soc. In press.

11. Sorm, F. and Cerna, J. Collection Czech. Chem. Commun. 25 (1960) 565.

12. Fowden, L. Ann. Rev. Biochem. 33 (1964) 173.

13. Thompson, J. F., Morris, C. J., Arnold, W. N. and Turner, D. H. In Holden, J. T. Amino Acid Pools, Elsevier, Amsterdam 1962, p. 54.

14. Sakato, Y. J. Agr. Chem. Soc. Japan 18 (1950) 262, 269; Chem. Abstr. 45 (1951) 3528.

15. Sasaoka, K. and Kito, M. Agr. Biol. Chem. (Tokyo) 28 (1964) 313.

16. Sasaoka, K., Kito, M. and Onishi, Y. Agr. Biol. Chem. (Tokyo) 28 (1964) 318.

17. Sasaoka, K., Kito, M. and Onishi, Y. Agr. Biol. Chem. (Tokyo) 28 (1964) 325.

18. Steiner, M. and Kamienski, E. S. v. Naturwiss. 42 (1955) 345.

19. Kjær, A., Conti, J. and Larsen, I. Acta Chem. Scand. 7 (1953) 1276.

20. Kjær, A. and Rubinstein, K. Acta Chem. Scand. 8 (1954) 598.

21. Larsen, P. O. Biochem. Biophys. Acta. In press.

22. Asatoor, A. and Dalgliesh, C. F. J. Chem. Soc. 19562291.

23. Greenstein, J. P. and Winitz, M. Chemistry of the Amino Acids 1116 , Wiley, New York 1961.

24. Feigl, F. Spot Tests in Organic Analysis, Elsevier, Amsterdam 1956, pp. 88 - 89.

25. Thompson, J. F., Arnold, W. N. and Morris, C. J. Nature 197 (1963) 380.

26. Tausz, J. and Putnocky, N. v. Ber. 52 (1919) 1573.

Received March 1, 1965.

Acta Chem. Scand. 19 (1965) No. 5 